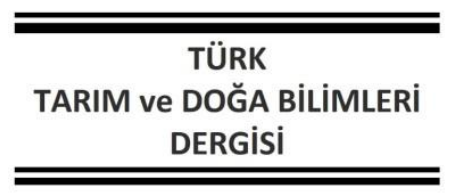

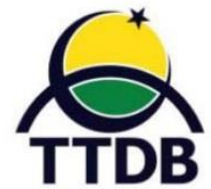

www.dergipark.gov.tr/turkjans

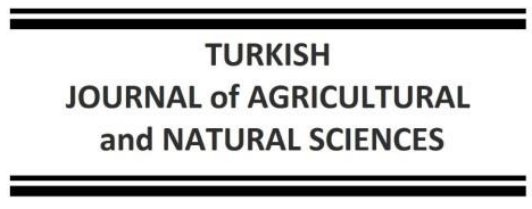

OURAL Of AGRICULTURAL \section{Araştırma Makalesi \\ - \\ Çapakçur Çayı Bazı Su Kalite Parametreleri Üzerine Bingöl Yerleşim Merkezinin (Kentleşmenin) Etkisi}

\author{
Yasin DEMiR ${ }^{1 *}$, Azize DOĞAN DEMiR² ${ }^{2}$ Hasan ER ${ }^{2}$, Orhan INIK $^{1}$ \\ ${ }^{1}$ Bingöl Üniversitesi, Ziraat Fakültesi, Toprak Bilimi ve Bitki Besleme Bölümü, Bingöl \\ ${ }^{2}$ Bingöl Üniversitesi, Ziraat Fakültesi, Biyosistem Mühendisliği Bölümü, Bingöl \\ *Sorumlu Yazar: ydemir@bingol.edu.tr
}

Geliş Tarihi: 11.08.2021 Düzeltme Geliş Tarihi: 14.10.2021 Kabul Tarihi: 15.10.2021

\title{
Öz
}

Bu çalışma Çapakçur çayı suyunun bazı kalite parametreleri üzerine, yerleşim yerinin etkisini belirlemek için yürütülmüştür. Çalışmada Bingöl il merkezinden geçen Çapakçur çayı üzerinde il merkezinin giriş ve çıkışında 12 ay süresince her ay su örnekleri alınmıştır. Su örnekleri üzerinde, pH, Elektriksel iletkenlik (EC), Sodyum (Na+), Kalsiyum $\left(\mathrm{Ca}^{++}\right)$, Magnezyum $\left(\mathrm{Mg}^{++}\right)$, Potasyum $\left(\mathrm{K}^{+}\right)$, $\mathrm{Klor}\left(\mathrm{Cl}^{-}\right)$, Karbonat $\left(\mathrm{CO}_{3}{ }^{-}\right)$, Bikarbonat $\left(\mathrm{HCO}_{3}{ }^{-}\right.$ ), Krom (Cr), Kurşun (Pb), Demir (Fe), Kadmiyum (Cd), Nikel (Ni), Kobalt (Co), Bakır (Cu), Çinko (Zn), Arsenik (As), Civa $(\mathrm{Hg})$, Askıda Katı Madde (AKM) analizleri yapılmıştır. Analiz sonuçlarına göre yerleşim biriminin, suların krom, kobalt ve demir konsantrasyonunu istatistiksel olarak arttırdığı belirlenmiştir $(P<0.05)$. Diğer parametrelerin $(\mathrm{Hg}$, As ve AKM hariç) konsantrasyonlarında artışın olduğu, ancak istatiksel olarak önemsiz olduğu tespit edilmiştir. Civa ve askıda katı madde miktarının atık sularda izin verilebilir sınır değerlerin üstünde olduğu belirlenmiştir.

Anahtar kelimeler: Su kalitesi, su analizi, Çapakçur çayı, ağır metal

\section{The Effect of Bingöl City Center (Urbanization) on Some Water Quality Parameters of Çapakçur Stream}

\begin{abstract}
This study was carried out to determine the effect of settlement area on some quality parameters of Çapakçur stream water. In the study, water samples were taken every month for 12 months at the entrance and exit of the city center on the Çapakçur stream. On water samples, pH Electrical conductivity (EC), Sodium $\left(\mathrm{Na}^{+}\right)$, Calcium $\left(\mathrm{Ca}^{++}\right)$, Magnesium $\left(\mathrm{Mg}^{++}\right)$, Potassium $\left(\mathrm{K}^{+}\right)$, Chlorine $\left(\mathrm{Cl}^{-}\right)$, Carbonate $\left(\mathrm{CO}^{-}\right)$, Bicarbonate $\left(\mathrm{HCO}^{-}\right)$, Chromium ( $\mathrm{Cr}$ ), Lead (Pb), Iron (Fe), Cadmium (Cd), Nickel (Ni), Cobalt (Co), Copper (Cu), Zinc (Zn), Arsenic (As), Mercury ( $\mathrm{Hg})$, Suspended Solid Matter (SSM) analyzes have been made. According to the analysis results, it was determined that the settlement increased the chromium, cobalt and iron concentrations of the waters statistically $(P<0.05)$. It was determined that there was an increase in the concentrations of other parameters $(\mathrm{Hg}$, As and SSM), but it was statistically insignificant. It has been determined that the amount of mercury and suspended solids is above the allowable values
\end{abstract}

Key words: Water quality, water analysis, Çapakçur stream, heavy metal.

\section{Giriş}

Su canlıların yaşaması için hayati bir öneme sahiptir. Su, insan vücudunun üçte ikisinden fazlasını oluşturur; insan beyninin yüzde 95'i, kanının 82'si ve akciğerlerinin yüzde 90'ı sudan meydana gelmektedir. Nüfus artışı, tatlı su kaynaklarının azalması, su kalitesinde meydana gelen bozukluklar bu kaynakları çok daha önemli hale getirmektedir. Su kaynakları, üzerindeki talebin giderek artışının yanında zaman ve konuma göre bu kaynağın arzu edilen miktar ve kalitede bulunmaması, mevcut su kaynaklarının ekonomik, 
çevresel ve sosyal faydalar içinde en verimli şekilde kullanımını yani yönetimini gerekli kılmaktadır (Meriç, 2004). Su kaynakları yönetimi doğal çevrim içerisinde suyun insanlar tarafından gerek nicelik gerekse nitelik olarak en verimli şekilde ekonomik, sosyal ve çevresel faydalar içinde sistematik olarak kullanımı anlamına gelmektedir. Sanayi, evsel atıklar ve tarımsal faaliyetler sonucu kirlenen sular, beraberinde birçok sorunu meydana getirmektedir. Fiziksel olarak herhangi bir değişiklik göstermeyen sular kimyasal içerik olarak kullanılamaz bir niteliğe sahip olabilmektedir. Şehirlerde içme ve kullanma suyu olarak kullanılan sular kırsal kesimde tarımsal faaliyetlerde de kullanılmaktadır. Ancak belirli standartların dışına çıkan sular sağlık saçısından ciddi problemler yaratmaktadır.

Su kirliliği suyu istenen kullanım amacı için uygunsuz hale getiren herhangi bir fiziksel, kimyasal veya biyolojik değişiklik olarak tanımlanabilir. Kanalizasyon, endüstriyel kimyasallar, endüstriyel işlemlerden kaynaklanan ağır metaller ve ev temizleyicileri, genellikle akarsulara ve nehirlere boşaltılan kirlilik kaynaklarına örnektir. Bununla birlikte su kirleticileri arasında kimyasallar, böcek ilaçları, gübreler, motor yağı, altlık ve kirli yüzey akışının diğer bileşenleri bulunur. Su ayrıca havadan gelen kirleticilerle de kirlenebilir, bu süreç atmosferik biriktirme olarak adlandırılır (Ouyang, 2005). Bu kirleticilerin kaynağını bulmak, kirletici etmenleri yok etmek ya da minimum düzeyde tutabilmek için su kaynakların düzenli ve periyodik olarak kalite parametrelerinin belirlenmesi ve izlenmesi gerekmektedir. Su kalitesinin bozulması, alg çoğalmasına, suyun tadının ve kokusunun değişmesine ve içme suyu arıtma maliyetinin artırmasına neden olabilmektedir (Tsegaye ve ark., 2006). Aynı şekilde su kalitesinin çeşitli faktörlerin etkisiyle bozulması neticesinde, tarımsal sulama ile birlikte toprakların fiziksel ve kimyasal özelliklerini olumsuz yönde etkiler (Demir ve Demir, 2019).

Bu çalışmanın amacı, Çapakçur havzasından doğup Bingöl il merkezinden geçerek Murat nehrine dökülen Çapakçur çayının bazı kalite parametreleri üzerine Bingöl il yerleşim yerinin etkisini belirlemektir.

\section{Materyal ve Metot}

Bu çalışma Bingöl il merkezinden geçen Çapakçur çayı üzerinde yapılmıştır. Çapakçur çayı Bingöl il merkezinin yaklaşık $40 \mathrm{~km}$ batısında yaralan dağlardan doğarak Bingöl il merkezini $2 \mathrm{~km}$ geçtikten sonra güneye doğru yönelerek Genç ilçesine yakın bir noktada Murat nehrine dökülür. Çay yatağının yaklaşık 5 km'lik kısmı Bingöl il merkezinden geçmektedir (Şekil 1).

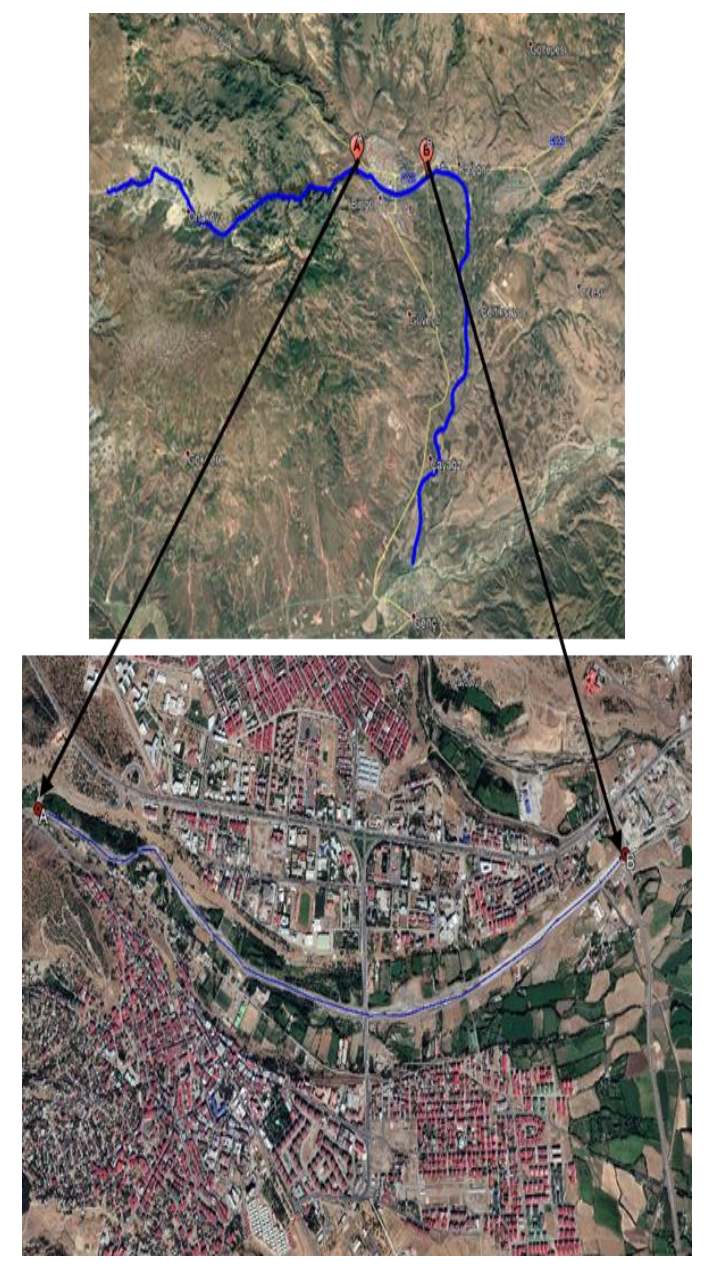

Şekil 1. Çalışma alanı (Çapakçur çayı) ve örnekleme noktaları (A ve B)

Çapakçur çayı üzerinde su örnekleme çalışmaları için 2 nokta belirlenmiştir. Bu noktalardan birincisi (A) il merkezinin batısında şehir merkezi girişinde ikinci örnekleme noktası (B) ise şehir merkezinin çıkışında yer almaktadır. Bu noktalardan aylık olarak 3 tekerrürlü su örneklemesi yapılmıştır. Su örneklerinin analizii için ilk olarak her bir örneğe derişik nitrik asit $\left(\mathrm{HNO}_{3}\right)$ çözeltisi eklenerek pH'ın 1.5 - 2.0 aralığına getirilmesiyle başlanmıştır. Bu örnekler +4 C de dlolaplarda muhafaza edilmiştir. Su örneklerinin ağır metal konsantrasyonları Bingöl Üniversitesi Merkezi Laboratuvar Uygulama Ve Araştırma Merkezinde bulunan ICP-MS cihasında belirlenmiştir. Analiz öncesinde hem askıda katı made belirlenmesi hemde su numunlerindeki partiküllerin ICP-MS cihazına zarar vermemesi için örnekler 125 mm filtre kağdındna süzülmüştür. Su örnekleri üzerinde yapılan analizler Çizelge $1^{\prime}$ de verilmiştir. Çalışma sonucunda elde edilen verilerin istatistiksel değerlendirmesi SPSS 15.0 paket programı kullanılarak yapılmıştır. 
Çizelge 1. Su örneklerinde belirlenen parametreler

\begin{tabular}{lll}
\hline Parametreler & Yöntemler & Referanslar \\
\hline $\mathrm{pH}$ & Standart & (Tüzüner, 1990) \\
Elektriksel iletkenlik (EC) & Standart & (Tüzüner, 1990) \\
Sodyum $\left(\mathrm{Na}^{+}\right)$ & Fotometrik yöntem & (Tüzüner, 1990) \\
Kalsiyum $\left(\mathrm{Ca}^{++}\right)$ & Fotometrik yöntem & (Tüzüner, 1990) \\
Magnezyum $\left(\mathrm{Mg}^{++}\right)$ & Titrimetrik yöntem & (Tüzüner, 1990) \\
Potasyum $\left(\mathrm{K}^{+}\right)$ & Fotometrik yöntem & (Tüzüner, 1990) \\
Klor $\left.(\mathrm{Cl})^{-}\right)$ & Titrimetrik yöntem & (Tüzüner, 1990) \\
Karbonat $\left(\mathrm{CO}_{3}{ }^{-}\right)$ & Titrimetrik yöntem & (Tüzüner, 1990) \\
Bikarbonat $\left(\mathrm{HCO}_{3}{ }^{-}\right)$ & Titrimetrik yöntem & (Tüzüner, 1990) \\
Krom (Cr) & ICP-MS yöntemi & (Nollet ve De Gelder 2000) \\
Kurşun (Pb) & ICP-MS yöntemi & (Nollet ve De Gelder 2000) \\
Demir (Fe) & ICP-MS yöntemi & (Nollet ve De Gelder 2000) \\
Kadmiyum (Cd) & ICP-MS yöntemi & (Nollet ve De Gelder 2000) \\
Nikel (Ni) & ICP-MS yöntemi & (Nollet ve De Gelder 2000) \\
Kobalt (Co) & ICP-MS yöntemi & (Nollet ve De Gelder 2000) \\
Bakır (Cu) & ICP-MS yöntemi & (Nollet ve De Gelder 2000) \\
Çinko (Zn) & ICP-MS yöntemi & (Nollet ve De Gelder 2000) \\
Arsenik (As) & ICP-MS yöntemi & (Nollet ve De Gelder 2000) \\
Civa (Hg) & ICP-MS yöntemi & (Nollet ve De Gelder 2000) \\
Askıda Katı Madde (AKM) & Gravimetrik yöntem & (Nollet ve De Gelder 2000) \\
\hline
\end{tabular}

\section{Bulgular ve Tartışma}

Su örneklerinin analiz sonuçlarına ilişkin tanımlayıcı istatistik verileri Çizelge 2'de verilmiştir. $\mathrm{Su}$ örneklerinde belirlenen parametrelerin ortalamaları incelendiğinde $\mathrm{As}, \mathrm{Hg}$ ve AKM hariç genel olarak B noktasındaki suların element konsantrasyonu A noktasından fazla bulunmuştur. $\mathrm{Bu}$ durum A ve B noktaları arasında kalan alanda Çapakçur çayının doğal veya suni birçok faktörün etkisinde olduğunu açıklamaktadır. Çapakçur çayına A ve B noktaları arasına doğal olarak herhangi bir akarsuyun katılmadığı düşünüldüğünde evsel atık, tarımsal faaliyetler ya da başka faktörlerin su konsantrasyonunun değişimi üzerinde etkili oldukları belirtilebilir. Çapakçur Çayının Bingöl il merkezi sınırları içeresinde şehir giriş ve şehir çıkış su örneklerinin incelenen kalite parametreleri Şekil 2'de verilmiştir.

Çapakçur çayı üzerinde örnekleme noktası olarak seçilen istasyonlara ait analiz sonuçları istatistiksel olarak incelendiğinde sadece $\mathrm{Fe}, \mathrm{Cr}$ ve Co elementlerinin anlamlı bir artış gösterdiği saptanmıştır $(P<0.05)$. Diğer parametrelerde ise genel olarak bir artış söz konusu olmasına rağmen istatistiksel olarak önemli bir farklılık bulunmamıştır. A ve B örnekleme noktalarında suların ortalama $\mathrm{Fe}, \mathrm{Cr}$ ve $\mathrm{Co}$ konsantrasyonları sırasıyla 7.683 -9.479 ppb, 0.136-0.156 ppb, 0.0060.007 ppb olarak belirlenmiştir. Bu değerler bazı ağır metallerin "T.C. Çevre ve Şehircilik Bakanlığı Su
Kirliliği Kontrolü Yönetmeliği"ne göre izin verilen üst değerlerinin altındadır. Dolayısıyla bu elementler için herhangi bir ağır element kirliliğinden bahsetmek söz konusu değildir (Anonim, 2020a). Fe elementi yer kabuğunda en fazla bulunan elementlerin başında gelir. Tarımsal gübreleme ve ilaçlama ile evsel ve endüstriyel atıklardan kaynaklı olarak sularda Fe kirliliği meydana gelebilmektedir. Sularda Fe iki formda $\left(\mathrm{Fe}^{+2}\right.$ ve $\left.\mathrm{Fe}^{+3}\right)$ bulunabilir. Çoğunlukla $\mathrm{Fe}^{+2}$ yeraltı sularında bulunur. Fe değişimine uğrayabildiğinden sulardan uzaklaştırılması zor olur (Anonim 2020b). $\mathrm{Cr}$ elementinin kâğıt endüstrisi, kimya sanayi, gübreler, metal işleri ve dökümhaneler, deri tabaklama, enerji santralleri gibi çok geniş uygulama alanları vardır (Önder, 2012; Seven ve ark., 2018). Çapakçur çayında A örnekleme istasyonu ile B istasyonundan alınan suların $\mathrm{Cr}$ konsantrasyonları arasında istatistiksel olarak önemli fark bulunmuştur. Suyun iki istasyon arasındaki faaliyetler sonucunda $\mathrm{Cr}$ bakımından zenginleştiği belirlenmiştir. Anılan bölgede herhangi bir sanayi kuruluşu bulunamamakla beraber tarım ve hayvancılık faaliyetleri yoğun olarak yapılmaktadır. Sudaki $\mathrm{Cr}$ artışının en fazla çeşitli kimyevi gübreler ve tarımsal ilaçlardan kaynaklandığı söylenebilir. 
Çizelge 2. Örnekleme noktalarından alınan su örnekleri verilerine ait tanımlayıcı istatistik değerleri

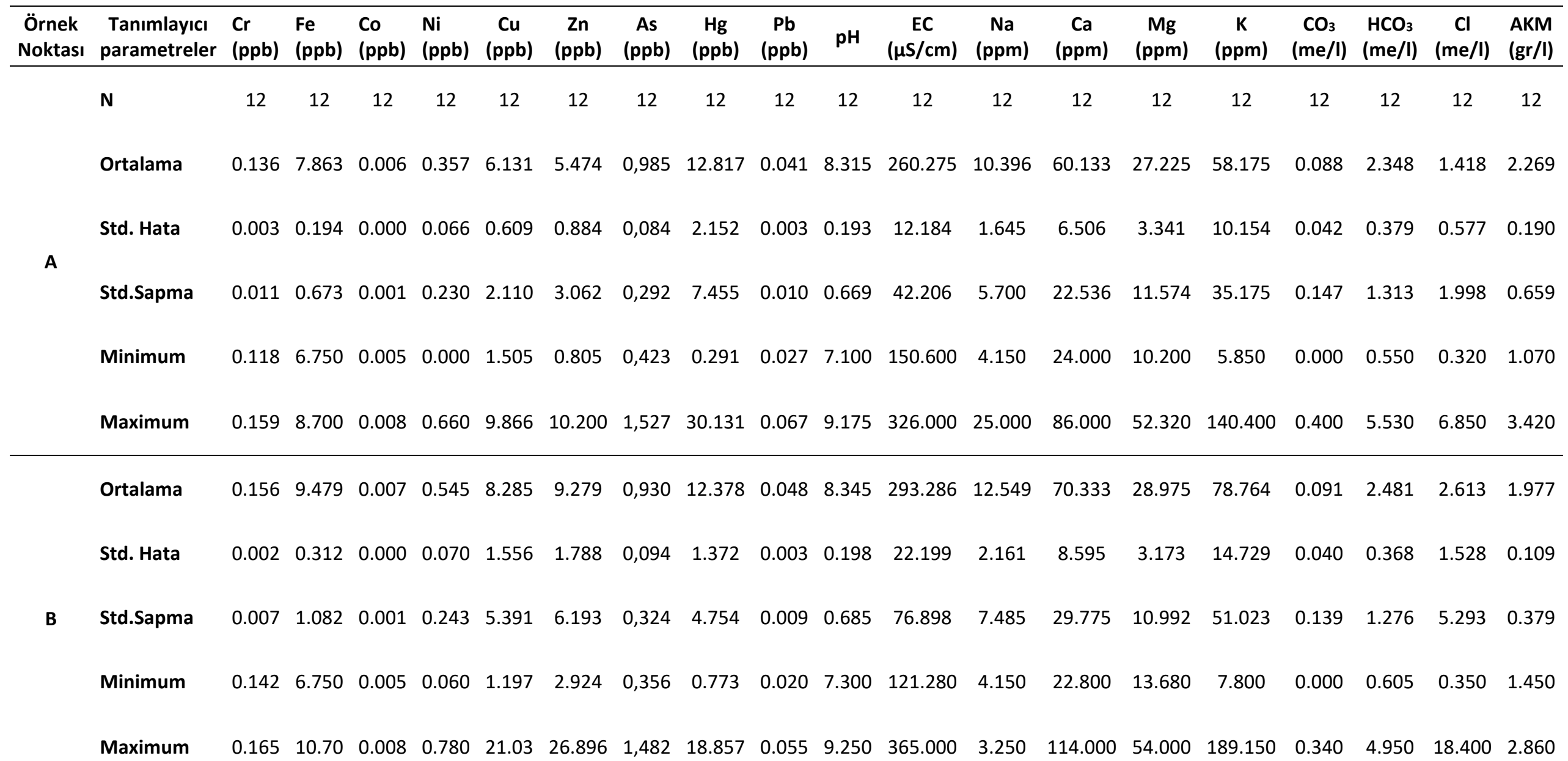

Cr:Krom, Fe: Demir, Co: Kobalt, Ni: Nikel, Cu: Bakır, Zn: Çinko, As: Arsenik, Hg: Civa, Pb: Kurşun, EC: Elektriksel iletkenlik, Na: Sodyum, Ca: Kalsiyum, Mg: Magnezyum, K: Potasyum, CO ${ }_{3}$

Karbonat, $\mathrm{HCO}_{3}$ : Bikarbonat, $\mathrm{Cl}$ : Klor, AKM: Askıda katı madde miktarı 

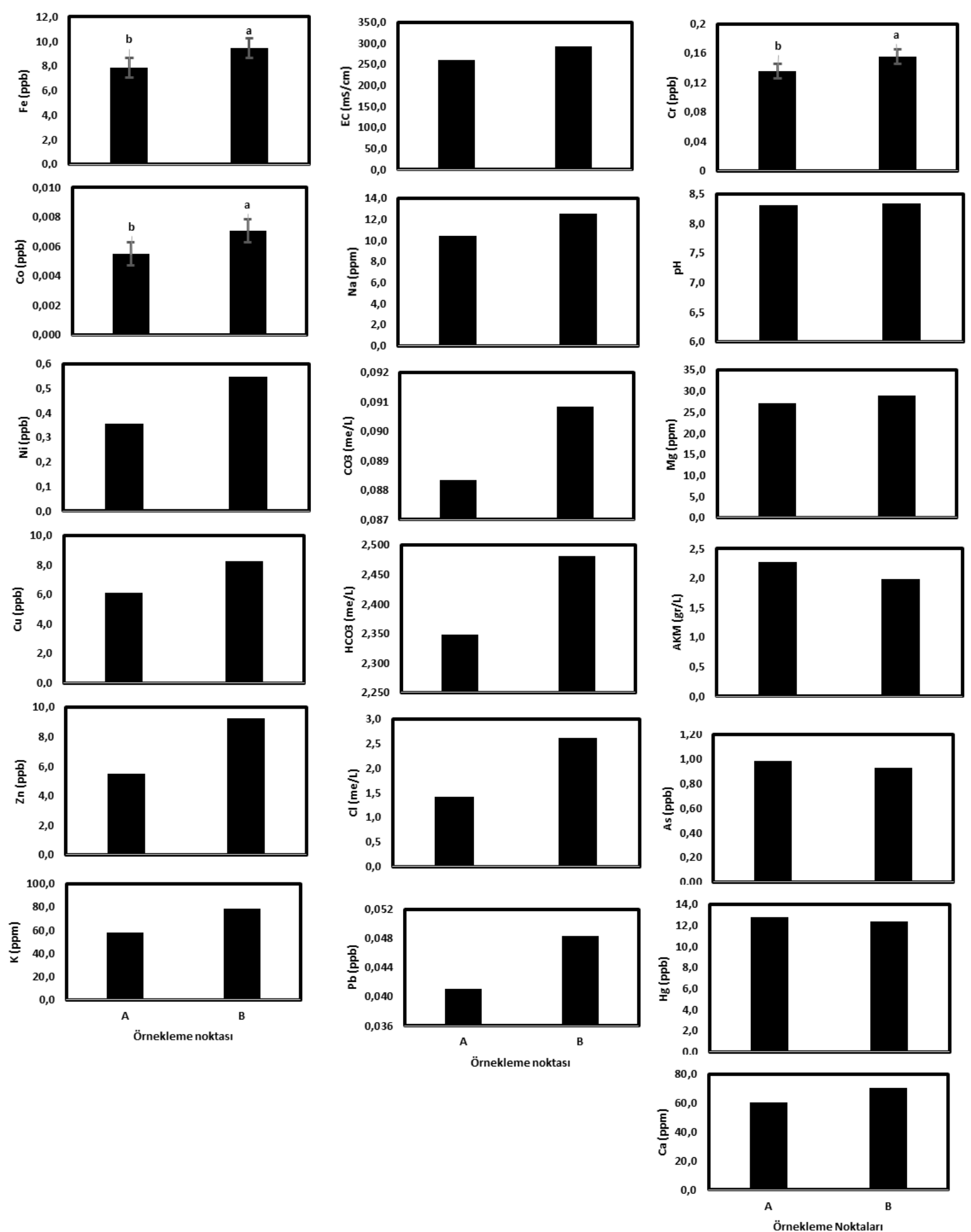

Şekil 2. Çapakçur Çayının Bingöl il merkezi sınırları içeresinde şehir giriş ve şehir çıkış su örneklerinin incelenen kalite parametreleri. 
Toprak, bitki ve hayvan bünyesinde çok az miktarda bulunur (Okudan, 2009). Örnekleme noktaları arasında suların Co konsantrasyonunu arttıracak herhangi bir sanayi kuruluşu bulunmamaktadır. Kobalt artışına neden olarak toprak, bitki ve hayvansal üretim faaliyetlerinin neden olduğu düşünülmektedir. Co, yüzey sularında küçük konsantrasyonlarda, çoğu zaman birkaç $\mu \mathrm{g}$ arasında bulunur. Saf yüzey sularındaki tipik kobalt konsantrasyonları $0.05 \mu \mathrm{g}-\mathrm{L}$ 'dir. Doğal olarak oluşan sularda kobalt az miktarda bulunur, nehir sularındaki ortalama doğal içeriği yaklaşık 0.2 $\mu \mathrm{g}-\mathrm{L}$ dir (Barałkiewicz ve Siepak, 1999). Bazı araştırıcılar tarafından yapılan çalışmalar neticesinde Aksu çayında Fe konsantrasyonu 1.658 ppm (Toroğlu ve ark., 2006), Yeşilırmak'ta 0.014 ppm, Kızılırmakta 0.553 ppm (Arıman ve ark., 2007) ve Karasu ırmağında 0.05 ppm (Sönmez ve ark., 2012) olarak bulunmuştur. Bu sonuçlar göz önüne alındığında Çapakçur çayının Fe konsantrasyonu ortalaması bu akarsuların altındadır. Bununla birlikte $\mathrm{Hg}$ ve AKM hariç diğer parametrelerinde izin verilebilir sınırlar dâhilinde kaldığı saptanmıştır. Ancak suların $\mathrm{Hg}$ ve AKM konsantrasyonları "T.C. Çevre ve Şehircilik Bakanlığı Su Kirliliği Kontrolü Yönetmeliği"nde belirtilen izin verilebilir sınırların çok üzerindedir. Evsel atıklar, yüzey ve yer altı su kaynaklarını önemli derecede kirletmektedir. Özellikle temizlik ve dezenfektan ürünleri suya karıştıklarında birçok ağır metal kirliliğine neden olmaktadır.

Çapakçur çayının doğduğu Çapakçur havzası erozyon riski yüksek bir bölgedir. Oldukça engebeli bir topoğrafik yapıya sahip olması toprak kayıplarını artan yönde etkilemektedir (Demir ve Mirici, 2020). Çapakçur çayında her iki örnekleme noktasında ölçülen ortalama AKM miktarı bu bilgiyi doğrulamaktadır. Taşınan sediment miktarının yüksek olması su kalitesinin de bozulmasına neden olmaktadır. Akarsuların su kalitesi parametreleri üzerine, akarsu hattının geçtiği bölgedeki faaliyetlerin (tarım, sanayi, kentleşme) türü ve yoğunluğu önemli derece etki eder. Örneğin Ouyang ve ark., (2006) çalışmalarında Çinin en gelişmiş bölgesi olan Pearl River Deltası Ekonomik Bölgesinde meydana gelen kentleşmenin nehir suyu kalitesine önemli oranda etki yaptığını saptamışlardır. Bölgede yapılan landsat uydu görüntüleri ve su kalitesi analizlerine göre kentleşmenin hızı ile kentsel nehir suyunun kirlilik seviyeleri arasında pozitif bir ilişki olduğunu göstermiştir. Aynı şekilde Giri ve Qiu (2016) çalışmalarında dünyanın dört bir yanındaki su kalitesinin, öncelikle hızlı kentleşmeyle bağlantılı yoğun tarımsal faaliyetler nedeniyle düştüğünü rapor etmişlerdir. Başka bir çalışmada Qin ve ark. (2014) Çin'deki Shenzhen Nehri havzasındaki 1985-
2009 arasındaki hızlı kentleşme döneminde su kalitesi değişikliklerinin nedenlerini araştırarak altyapı geliştirme ve sosyo-ekonomik politikalarla ilgili değişiklikleri incelemişlerdir ve su kalitesinin son yıllarda kademeli olarak iyileşmeden önce erken kentleşme aşamalarında hızla bozulduğunu ve evsel deşarjdaki hızlı artışların su kalitesinin bozulmasının başlıca nedenleri olduğunu belirtmişlerdir. Literatür bilgilerinde saptanan sonuçlarla bu çalışmanın sonuçları paralellik göstermektedir. Bingöl il merkezinin giriş ve çıkış noktalarında Çapakçur suyunun bazı parametrelerinde meydana gelen artışlar kentleşme veya diğer faaliyetlerin etkili olabildiğini göstermektedir. Bu çalışmanın devamı olarak Çapakçur suyu kalitesinin düzenli olarak izlenmesi sürdürülebilir ve bu durum su yönetimi açısından önem arz etmektedir.

\section{Sonuç ve Öneriler}

Çapakçur çayında yerleşim biriminin su kalite parametrelerine olan etkisini belirlemek için 12 ay boyunca şehir girişi (A) ve şehir çıkışı (B) noktasından her ay su örneklemesi yapılmıştır. Su örneklerinin bazı ağır metal, anyon ve katyon içerikleri saptanmıştır. Elde edilen sonuçlara göre yerleşim yerinin Çapakçur çayında demir, krom ve kobalt konsantrasyonunun istatistiksel olarak arttırdığı saptanmıştır. Bununla birlikte arsenik, civa ve askıda katı madde miktarları dışında diğer bütün elementlerin konsantrasyonunun arttığı ancak istatiksel olarak önemli bulunmadığı ortaya çıkmıştır. Çapakçur çayında suların Civa ve Askıda katı madde miktarının "T.C. Çevre ve Şehircilik Bakanlığı Su Kirliliği Kontrolü Yönetmeliği”nde belirtilen izin verilebilir sınırların üzerinde çıktığı görülmüştür. Örnekleme noktaları arasında kalan yerleşim biriminde tarım ve hayvancılık faaliyetleri ile olası evsel atıkların Çapakçur çayı su kalitesini olumsuz yönde etkilediği düşünülmektedir. Su kalitesinde meydana gelebilecek olumsuzluğun önüne geçebilmek için ilgili alanda tarımsal ve evsel atıkların Çapakçur çayına karışmadan bertaraf edilmesi gerekmektedir.

\section{Teşekkür}

Bu çalışma Bingöl Üniversitesi Bilimsel Araştırma Projeleri (BÜBAP) ve Pilot Üniversite Koordinasyon Merkez Birimi (PIKOM) eşgüdümünde yürütülen Pikom. Bitki-2018.001 nolu proje kapsamında desteklenmiştir.

Çıkar Çatışması Beyanı: Makale yazarları aralarında herhangi bir çıkar çatışması olmadığını beyan ederler. 
Araştırmacıların Katkı Oranı Beyan Özeti: Yazarlar makaleye eşit oranda katkı sağlamış olduklarını beyan ederler.

\section{Kaynaklar}

Anonim, 2020a. [Erişim tarihi 10 Eylül 2020]. Erişim linki:

https://www.mevzuat.gov.tr/mevzuat?Me vzuatNo $=7221 \&$ sourceXmlSearch $=\& M e v z$ uatlliski=0\&MevzuatTur=7\&MevzuatTerti $\mathrm{p}=5$

Anonim, 2020b. [Erişim tarihi 10 Eylül 2020]. Erişim linki: http://akarecevre.com/su-analizlerive-etkileri/

Arıman, S., Cüce, H., Özbayra, E., Bakan, G., Büyükgüngör, H. 2007. Orta Karadeniz Kıyı Şeridi Nehirleri Su ve Sediman Ortalamalarında Ağır Metal Kirliliği. 7. Ulusal Çevre Mühendisliği Kongresi, 24-27 Ekim, İzmir, s. 864-868.

Barałkiewicz, D., Siepak, J. 1999. Chromium, nickel and cobalt in environmental samples and existing legal norms. Polish Journal of Environmental Studies, 8(4): 201-208.

Demir, Y., Demir, A.D. 2019. Determination and Evaluation of Irrigation Water Quality in Areas Irrigated with Groundwater in the Southeast of Harran Plain. Turkish Journal of Agriculture-Food Science and Technology, 7(11): 1894-1900.

Demir, Y., Mirici, M.E. 2020. Effect Of Land Use And Topographic Factors On Soll Organic Carbon Content And Mappıng Of Organıc Carbon Distribution Usıng Regression Krıgıng Method. Carpathıan Journal of Earth And Environmental Sciences, 15(2): 311-322.

Giri, S., Qiu, Z. 2016. Understanding the relationship of land uses and water quality in twenty first century: a review. Journal of environmental management, 173: 4148.

Meriç, B.T. 2004. Su kaynakları yönetimi ve Türkiye . Jeoloji Mühendisliği Dergisi, 28(1): 27-38.

Nollet, L.M. and De Gelder, L.S. 2000. Handbook of water analysis. CRC press.

Okudan, M. 2009. Kobalt ve Molibden İçeren Kullanılmış Hidrodesülfürizasyon (HDS) Katalizör Atıklarına Asidik Ve Alkali Liç Uygulaması, Yüksek Lisans Tezi, Süleyman Demirel Üniversitesi Fen Bilimleri Enstitüsü, Isparta.

Ouyang, T., Zhu, Z., Kuang, Y. 2006. Assessing impact of urbanization on river water quality in the Pearl River Delta Economic Zone, China. Environmental Monitoring and Assessment, 120(1): 313-325.
Ouyang, Y. 2005. Evaluation of river water quality monitoring stations by principal component analysis. Water research, 39(12): 2621-2635.

Önder, S. 2012. Atıksular ile Sulanan Zirai Alanlardaki Ağır Metal Kirliliğinin Araştırılması. Yüksek Lisans Tezi, Selçuk Üniversitesi Fen Bilimleri Enstitüsü, Konya.

Qin, H. P., Su, Q., Khu, S. T., Tang, N. 2014. Water quality changes during rapid urbanization in the Shenzhen River Catchment: An integrated view of socio-economic and infrastructure development. Sustainability, 6(10), 7433-7451.

Seven, T., Büşra, C., Darende, B.N. ve Sevda, O. 2018. Hava ve toprakta ağır metal kirliliği. Ulusal Çevre Bilimleri Araştırma Dergisi, 1(2): 91-103.

Sönmez, A., Hisar, O., Yanık, T. 2012. Karasu Irmağında ağır metal kirliliğinin tespiti ve su kalitesine göre sınıflandırılması. Atatürk Üniversitesi Ziraat Fakültesi Dergisi, 43(1): 69-77.

Toroğlu, E., Toroğlu, S., Alaeddinoğlu. F. 2006. Aksu Çayında akarsu Kirliliği. Coğrafi Bilimler Dergisi, 4(1): 93-103.

Tsegaye, T., Sheppard, D., Islam, K. R., Tadesse, W., Atalay, A., Marzen, L. 2006. Development of chemical index as a measure of instream water quality in response to landuse and land cover changes. Water, Air, and Soil Pollution, 174(1): 161-179.

Tüzüner, A. 1990. Toprak ve su analiz laboratuvarları el kitabı. Tarım Orman ve Köy İşleri Bakanlığı, Köy Hizmetleri Genel Müdürlüğü, Ankara. 